\title{
Arroyo de las Almas (La Fregeneda, Salamanca): un nuevo sitio con arte paleolítico al aire libre*
}

\author{
Arroyo de las Almas (La Fregeneda, Salamanca): a new site with open-air Palaeolithic art
}

\author{
Carlos Vázquez Marcos ${ }^{\mathrm{a}}$ y Mário Reis ${ }^{\mathrm{b}}$
}

\section{RESUMEN}

El conjunto rupestre al aire libre del Arroyo de las Almas (La Fregeneda, Salamanca), situado junto al encuentro de los ríos Águeda y Duero, tiene, al menos, 600 motivos grabados con una amplia secuencia temporal que transcurre desde el Paleolítico Superior hasta nuestros días. Mostramos aquí, por primera vez, los 21 motivos paleolíticos, grabados todos ellos por incisión, e integrables en el Magdaleniense.

\begin{abstract}
The open-air rock art collection of Arroyo de las Almas, located next to the confluence of the Águeda and Duero rivers, has at least 600 engraved motifs with a long temporal sequence that runs from the Upper Palaeolithic to the present. We present for the first time the 21 recorded Palaeolithic motifs, all engraved by incision, and belonging to the Magdalenian period.
\end{abstract}

Palabras clave: Arte rupestre; Paleolítico Superior; Magdaleniense; Cuenca del Duero; Grabados; Península ibérica.

Key words: Rock art; Upper Palaeolithic; Magdalenian; Douro Basin; Engravings; Iberian peninsula.

\section{INTRODUCCIÓN}

En esta breve nota presentamos 21 nuevos motivos grabados paleolíticos descubiertos en el conjunto ru- pestre de Arroyo de las Almas (Fig. 1). Los hemos agrupado en tres categorías temáticas, 13 zoomorfos, 7 signos y 1 motivo indeterminable. También se ha catalogado un variado grupo no figurativo de grabados paleolíticos, compuesto por trazos aislados o conjuntos de trazos aparentemente inconexos. Todos ellos están ejecutados mediante la técnica de grabado inciso. Los autores de esta aportación los localizaron en 5 rocas de pizarras y esquistos, a partir del mes de septiembre de 2015 (Reis y Vázquez Marcos 2015).

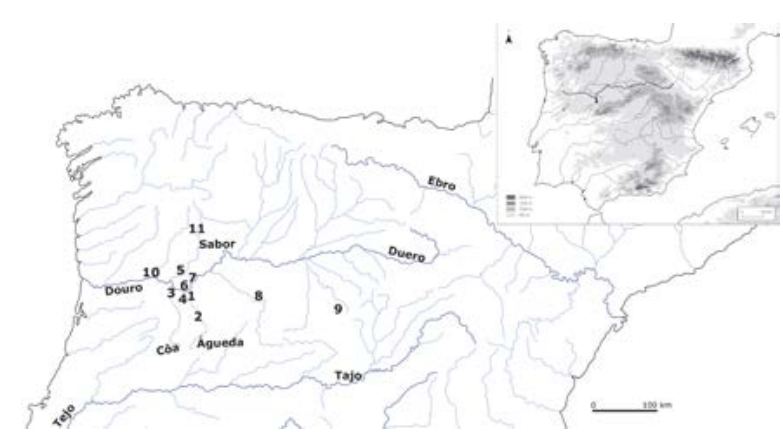

Fig. 1. Localización en la cuenca del Duero de los sitios o conjuntos de sitios con arte Paleolítico al aire libre: 1. Arroyo de las Almas; 2. Siega Verde; 3. Conjunto del arte del Côa; 4. Redor do Porco; 5. Bajo Sabor (Medal, Ribeira da Sardinha y Pedra de Asma); 6. Fraga do Gato; 7. Mazouco; 8. La Salud; 9. Conjunto de Domingo García; 10. Foz do Tua; 11. Alto Sabor (Sampaio, Pousadouro y Fraga Escrevida).

* La prospección y posteriores investigaciones desarrolladas por los autores de este artículo carecieron de financiación proveniente de los sectores público, comercial o no lucrativo.

El correspondiente permiso administrativo, para dicha prospección, fue otorgado en 2015 por la Junta de Castilla y León. Servicio Territorial de Cultura. Resolución de la Dirección General de Patrimonio Cultural. Número de Expediente : 46/2015-SA SEH/CEV

a GIR PREHUSAL. Dpto. de Prehistoria, Historia Antigua y Arqueología. Facultad de Geografía e Historia. Universidad de Salamanca. Correo e.: carlosvazquezmarcos@gmail.com http://orcid.org/0000-0001-6377-6832

b Fundação Côa Parque. Rua do Museu. 5150-620 Vila Nova de Foz Côa, Portugal. Correo e.: marioreissoares@sapo.pt https://orcid.org/00000002-9135-0502

Recibido 5-III-2018; aceptado 13-VI-2018.

Copyright: (C) 2019 CSIC. Este es un artículo de acceso abierto distribuido bajo los términos de la licencia de uso y distribución "Creative Commons Reconocimiento 4.0 Internacional" (CC BY 4.0). 
El Arroyo de las Almas es el conjunto con arte rupestre paleolítico más relevante en la provincia de Salamanca, tras el yacimiento arqueológico de Siega Verde (Serranillo) (Alcolea y Balbín 2006, 2008; Bueno et al. 2008; Vázquez Marcos 2014, 2015, 2017) por su situación en la submeseta norte de la península ibérica y sus características formales, tipo de soporte, cronología, ambiente y estado de conservación. Además es uno de los más reseñables del territorio autonómico de Castilla y León. En el marco de la temática del Paleolítico Superior abordada, este nuevo lugar entronca con los nuevos descubrimientos artísticos al aire libre localizados en la península y en el resto del continente europeo (Welker 2016). Entre ellos destaca el gran grupo regional de arte paleolítico al aire libre de la cuenca del Duero, en el que se inserta Arroyo de las Almas (Balbín 2008; Baptista 1999, 2009; Baptista y Reis 2011; Figueiredo, Xavier et al. 2014; Figueiredo, Nobre et al. 2016; Garate et al. 2016; Reis 2012, 2013, 2014; Ripoll y Municio 1999; Santos 2017; Teixeira y Sanches 2017).

\section{ARROYO DE LAS ALMAS}

Este conjunto rupestre se sitúa en el término municipal de La Fregeneda (Salamanca), en la margen derecha de dicho arroyo y en varias de sus pequeñas y adyacentes riveras. El municipio está incluido en la comarca de Vitigudino y en la subcomarca del Abadengo, en la esquina noroccidental de la provincia comprendida entre los ríos Águeda, Yeltes, Huebra y Duero, e insertado en el espacio natural protegido del Parque Natural Arribes del Duero. Desde el punto de vista geomorfológico y paisajístico, el Arroyo de las Almas es un pequeño afluente del río Águeda que desemboca a $1 \mathrm{~km}$ de la entrada de este último en el Duero (Fig. 2).

\section{METODOLOGÍA EMPLEADA EN LA PROSPECCIÓN, DOCUMENTACIÓN Y ESTUDIO DE LOS HALLAZGOS}

En la prospección arqueológica partimos de un principio metodológico simple: donde hay afloramientos rocosos puede haber arte rupestre, y la única forma de confirmarlo es observar metódicamente las superficies disponibles.

Tras el descubrimiento de las primeras evidencias gráficas se dividió el entorno, para su mejor comprensión, en núcleos. Con posterioridad, hicimos una primera diagnosis de las rocas y paneles con grabados con luz natural y artificial de iluminación fría Led. Los motivos se documentaron mediante fotografías diurnas, nocturnas y calcos y se clasificaron a partir de las

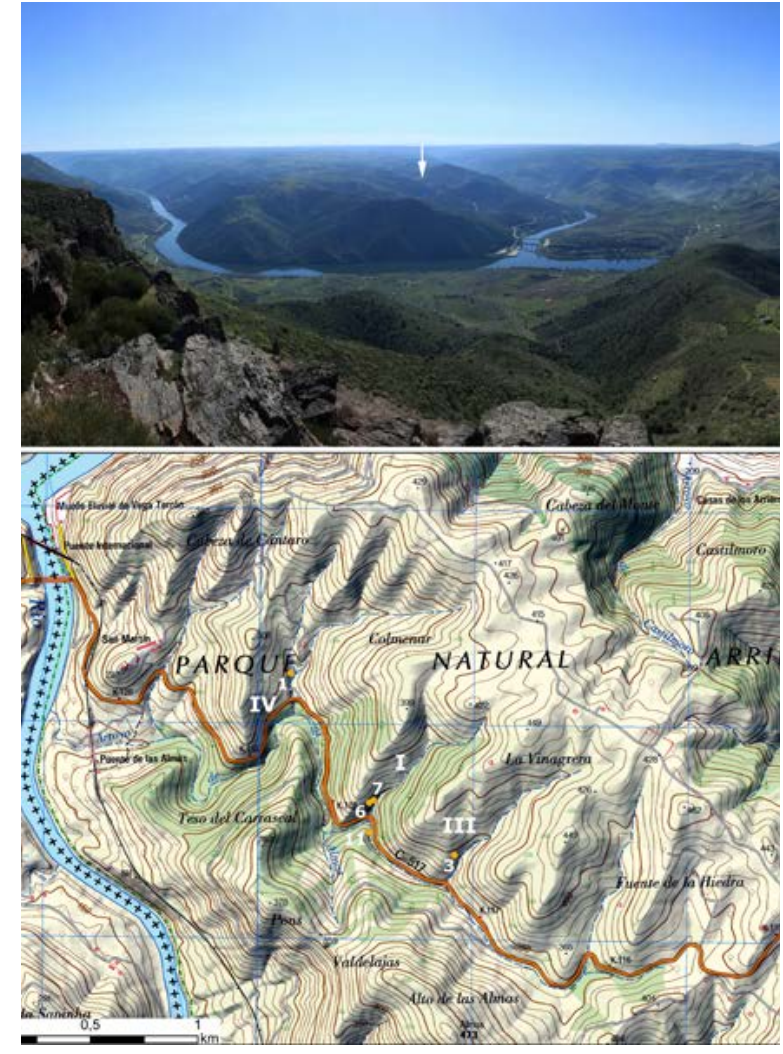

Fig. 2. La imagen superior está tomada desde la margen portuguesa del río Duero en la que se observa la desembocadura del Águeda bajo el puente internacional ferroviario. En el centro, señalado por la flecha, el Arroyo de las Almas (fotografía de Mário Reis, marzo 2017). La imagen inferior muestra la localización de las 5 rocas con grabados paleolíticos del Arroyo de las Almas (Fregeneda, Salamanca) en el Mapa Topográfico Nacional a escala 1: 25.000, hoja 448-bis-4 San Martín, año 2002 (fuente: Centro Nacional de Información Geográfica). Los números arábigos corresponden al de inventario de las rocas y los romanos al núcleo al que pertenecen. El Vértice Geodésico “Almas”, Número 44900, visible en el sector inferior del mapa, se encuentra a $473 \mathrm{~m} \mathrm{s.} \mathrm{n.} \mathrm{m.,}$ siendo sus coordenadas geográficas, Sistema ED 50, longitud: $-6^{\circ}$ 54' 24,1706 "; latitud: $41^{\circ} 00^{\prime} 26,6322$ " (fuente Instituto Geográfico Nacional, en color en la versión electrónica).

imágenes obtenidas y digitalizadas apoyándonos en programas informáticos específicos. Las fotografías se tomaron en la mejor hora del día, y de la noche, con una Canon 5D Mark II y diversos objetivos y flashes sincronizados en variadas posiciones.

\section{DESCRIPCIÓN DE LOS MOTIVOS PALEOLÍTICOS INVENTARIADOS}

Las rocas inventariadas en el conjunto rupestre de Arroyo de las Almas son 24, de las cuales 5 
tienen grabados paleolíticos. Los 'núcleos' definidos en el conjunto rupestre (números romanos) y las rocas y paneles grabados estudiados en esos 'núcleos' (números arábigos) se localizan en la figura 2. Los motivos paleolíticos zoomorfos (Fig. 3), signos o indeterminables se inventarían y describen en la Tabla 1.

\section{ANÁLISIS, VALORACIÓN Y PROPUESTA DE ADSCRIPCIÓN ESTILÍSTICA Y CRONOLÓGICA EN RELACIÓN CON OTROS CONJUNTOS PALEOLÍTICOS DE LA CUENCA DEL DUERO}

En la actualidad faltan datos precisos y objetivos utilizables para una datación fehaciente de la ejecución del conjunto gráfico paleolítico del Arroyo de las Almas. Hasta que se disponga de ellos el acercamiento morfológico, formal y estilístico es el único factible. Nunca deberá ser considerado como indiscutible pero es aún una variable esencial y nada desdeñable para entender las sociedades prehistóricas que ejecutan dichas manifestaciones, independientemente de su soporte (Leroi-Gourhan 1971; Rivero y Sauvet 2014).

En las 21 figuras contabilizadas predomina la temática zoomorfa sobre la abstracta (Tab. 1). Sin negar la influencia que el deficiente estado de con-

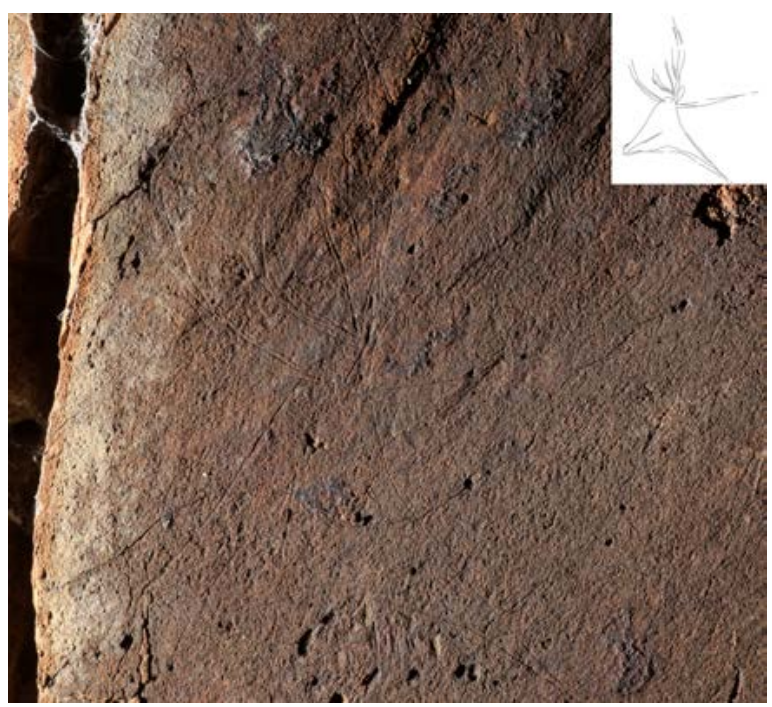

Fig. 3. Cabeza del grabado paleolítico de ciervo de la roca 6 del Núcleo I (motivo 1) con sus exuberantes astas (calcos en Fig. 4 superior y 6: 1; fotografia de Mário Reis, mayo 2018; en color en la versión electrónica). servación de alguno de los paneles y sus representaciones pudiera tener en la identificación, ese predominio es frecuente en los principales sitios con arte paleolítico al aire libre de la cuenca del Duero. Allí los animales son los motivos más documentados pese a que, por ejemplo, en Siega Verde los signos supongan más del $37 \%$ de las figuras inventariadas (Alcolea y Balbín 2006: 254-260). Sin embargo los paralelos con los motivos de este sitio arqueológico son pocos, excepto los lineales, que también están presentes en el Núcleo IV de Arroyo de las Almas.

En la cercana región artística portuguesa del valle del Côa no se ha cuantificado todavía la totalidad de los signos paleolíticos. Un trabajo reciente (Santos 2017) y otro en preparación por uno de nosotros (MR) nos permite afirmar que son poco frecuentes en su fase Graveto-Solutrense, aun existiendo algunos casos notables (Baptista 2009: 110). Sin embargo, en sus fases más recientes, como en el Magdaleniense y en el final del ciclo artístico paleolítico, sin ser tan abundantes como las figuras zoomorfas, hay rocas donde adquieren una gran importancia cuantitativa (Baptista 2009: 114-129).

En el conjunto protagonista de este trabajo los signos son escasos, además de tipológicamente simples y con frágiles paralelos con otros conjuntos del Paleolítico Superior. En su mayoría se asocian a figuras de animales, pudiéndose plantear como hipótesis que sean coetáneos. Cuando aparecen aislados, como en el panel 2 de la roca 1 del Núcleo IV, sin asociación directa a otras figuras paleolíticas, su atribución cronológica detallada es muy problemática.

Tampoco podemos acudir al estudio de las superposiciones entre las figuras paleolíticas de Arroyo de las Almas, un aspecto importante en los análisis de los conjuntos gráficos del Côa y Siega Verde, porque se reducen a alguna ocasional y poco relevantes entre trazos aislados y figuras de animales. Las superposiciones más evidentes afectan a los motivos lineales de cronología post-paleolítica (Figs. 4 y 5), ejecutados, en ocasiones, por encima de animales paleolíticos.

Otro claro indicador de la vinculación de este nuevo conjunto con el contexto artístico más cercano es la preeminencia de équidos y cérvidos entre los zoomorfos. En cambio no hay bovinos en Arroyo de las Almas, siendo los caprinos la tercera especie más representada. El hecho es un tanto extraño ya que en Siega Verde y en el valle del Côa los uros son habituales en el bestiario documentado.

Algunas figuras zoomorfas del Arroyo de las Almas tienen rasgos y atributos estilísticos de incontestable valor para acercarnos a una datación relativa del con-

Trab. Prehist., 76, N. ${ }^{\circ}$ 1, enero-junio 2019, pp. 138-146, ISSN: 0082-5638

https://doi.org/10.3989/tp.2019.12230 


\begin{tabular}{|c|c|c|c|c|}
\hline Mot. & $\begin{array}{l}\text { Núcleo-Roca- } \\
\text { Panel }\end{array}$ & Descripción & $\begin{array}{l}\text { Dim. } \\
(\mathbf{c m})\end{array}$ & Fase \\
\hline 1 & I-6-1 & $\begin{array}{l}\text { Ciervo con varias modalidades de trazos incisos simples, únicos y repetidos. Se localizó } \\
\text { en la parte alta del panel 1, en su lado izquierdo. Además de su cornamenta, hay una } \\
\text { rama trasera separada en varios candiles, bifurcados, y las tres puntas delanteras. La } \\
\text { cabeza es triangular con el morro redondeado. Aparece la línea naso-frontal, una larga } \\
\text { oreja, la boca y un despiece en el cuello-pecho indicativo de una diferente longitud del } \\
\text { pelaje y de su coloración en ese punto. Una fina línea señala el despiece escapular, su } \\
\text { línea cérvico-dorsal recta, la grupa y la cola corta. Carece de vientre pero están } \\
\text { representadas las extremidades anteriores y posteriores (en Y), una por par (Figs. 3, } 4 \\
\text { superior y } 6: 1 \text { ). }\end{array}$ & 24 & I \\
\hline 2 & I-7-1 & $\begin{array}{l}\text { Caprino (Fig. 6) con extremidades anteriores realizadas con un único trazo y las } \\
\text { posteriores, con pezuña y corvejón, rellenas con múltiples trazos. La cabeza tiene una } \\
\text { anómala forma sin más detalle anatómico, que dos largos cuernos curvos hacia atrás. } \\
\text { Su cuerpo y cuarto trasero muestran abundantes rellenados internos. Tiene una larga } \\
\text { cola finalizada en una peculiar forma en tridente, que junto a la rectitud de su línea } \\
\text { cérvico-dorsal nos impiden aseverar, de forma irrebatible, la asignación zoomorfa } \\
\text { propuesta. Esta figura, sin el naturalismo de otras, está asociada a dos conjuntos de } \\
\text { trazos. }\end{array}$ & 12 & II \\
\hline 3 & I-11-1 & $\begin{array}{l}\text { Motivo indeterminable que podría corresponder tanto al vientre y las extremidades } \\
\text { anteriores de un animal, que mira a la derecha del observador, como a un signo. A su } \\
\text { alrededor hay varios trazos grabados mediante incisión. }\end{array}$ & 11 & II \\
\hline 4 & III-3-2 & $\begin{array}{l}\text { Cérvido inciso mediante trazos únicos y repetidos. Sola falta su cabeza, aparentemente } \\
\text { no grabada. Tiene una pequeña cola, continuación de una lograda y recta línea } \\
\text { cérvico-dorsal, una inacabada línea del cuello-pecho y dos extremidades posteriores } \\
\text { ejecutadas mediante dos líneas sin cerrar en su final y con el corvejón. Un despiece } \\
\text { ventral señala el cambio cromático de su pelaje en este punto, la zona inguinal y tres } \\
\text { líneas incisas a la altura de la nuca que indicarían la pelambrera junto a la oreja y un } \\
\text { posible cuerno. El zoomorfo, situado en posición oblicua, y orientado hacia abajo, se } \\
\text { superpone a una línea curva que parece simular una pequeña loma o elevación además } \\
\text { de estar asociado a tres signos (Figs. } 4 \text { y 6). }\end{array}$ & 24 & I \\
\hline 5 & III-3-2 & $\begin{array}{l}\text { Signo constituido por un conjunto organizado de trazos oblicuos, verticales y } \\
\text { horizontales, en la parte superior del panel, de al menos } 25 \text { líneas grabadas mediante } \\
\text { incisión en trazo único. }\end{array}$ & 18 & I \\
\hline 6 & III-3-2 & $\begin{array}{l}\text { Signo oval, sin cerrar, situado por encima de la línea cérvico-dorsal del motivo } 4 \text {. } \\
\text { Tiene, en su interior, al menos } 7 \text { líneas finamente grabadas. Es similar al motivo 8, del } \\
\text { Núcleo IV. }\end{array}$ & 3 & I \\
\hline 7 & III-3-2 & $\begin{array}{l}\text { Signo segmentado y constituido por un trazo horizontal que se inicia junto a la } \\
\text { extremidad trasera del motivo } 4 \text {, superpuesto por } 5 \text { trazos pequeños, verticales y } \\
\text { paralelos, de diversas longitudes. }\end{array}$ & 8 & I \\
\hline 8 & IV-1-2 & $\begin{array}{l}\text { Signo oval cerrado, inciso en trazos únicos, en posición oblicua y con múltiples líneas } \\
\text { paralelas en su interior. Se sitúa a media altura y en el sector izquierdo del panel } 2 \text {, a } \\
\text { la izquierda del motivo } 9 \text {. }\end{array}$ & 2 & $\mathrm{I} / \mathrm{II}$ \\
\hline 9 & IV-1-2 & $\begin{array}{l}\text { Signo fusiforme. Se localizó en el sector intermedio y central del panel 2, a la derecha } \\
\text { del motivo } 8 \text {. }\end{array}$ & 7 & $\mathrm{I} / \mathrm{II}$ \\
\hline 10 & IV-1-6 & $\begin{array}{l}\text { Cabra incompleta en la parte inferior izquierda del panel } 6 \text {. Se han identificado sus dos } \\
\text { cuernos, con abundantes rellenados internos ejecutados con trazos lineales incisos y } \\
\text { verticales, similar al trazo múltiple, la línea naso-frontal, el morro redondeado y una } \\
\text { extremidad anterior como continuación del cuello-pecho. Tras su cabeza arranca la línea } \\
\text { cérvico-dorsal ejecutada con varios trazos múltiples sin que podamos observar la línea } \\
\text { del vientre u otros rasgos anatómicos. Su estilo subnaturalista es intencional (Fig. 6). }\end{array}$ & 7 & II \\
\hline 11 & IV-1-6 & $\begin{array}{l}\text { Posible cierva situada por debajo del motivo 10, a la izquierda. Está completa y pese a } \\
\text { sus pequeñas dimensiones y la dificultad que entraña su observación, es posible } \\
\text { apreciar su peculiar e irregular cabeza ovalada con una oreja, las líneas del cuello- } \\
\text { pecho y cérvico-dorsal, una corta y redondeada cola y la línea ventral. Está ejecutada } \\
\text { en trazos simples, repasados en el vientre y en el pecho (Fig. 6). }\end{array}$ & 5 & II \\
\hline
\end{tabular}

Tab. 1.[1] Relación y descripción de los motivos paleolíticos grabados por incisión e inventariados en el sitio del Arroyo de las Almas (Fregeneda, Salamanca). Dim. Dimensiones. 


\begin{tabular}{|c|c|c|c|c|}
\hline Mot. & $\begin{array}{l}\text { Núcleo-Roca- } \\
\text { Panel }\end{array}$ & Descripción & $\begin{array}{l}\text { Dim. } \\
(\mathbf{c m})\end{array}$ & Fase \\
\hline 12 & IV-1-6 & $\begin{array}{l}\text { Conjunto de líneas incisas aparentemente conectadas, con orientaciones divergentes. } \\
\text { Conforman un motivo abstracto de difícil clasificación, junto al motivo } 11 \text { y en la parte } \\
\text { inferior del panel } 6 \text {. }\end{array}$ & 8 & II \\
\hline 13 & IV-1-6 & $\begin{array}{l}\text { Cierva localizada en la extremidad derecha inferior del panel } 6 \text {, a la derecha del motivo } \\
\text { 10. Destaca su morro apuntado y las dos orejas, cortas, afiladas y en perspectiva } \\
\text { correcta, con abundantes trazos en su interior, una perceptible línea cérvico-dorsal, el } \\
\text { vientre abombado, la grupa, la cola, interrumpida por una grieta, y dos cortas } \\
\text { extremidades posteriores (Fig. 6). }\end{array}$ & 6 & I \\
\hline 14 & IV-1-6 & $\begin{array}{l}\text { Prótomo de cierva, a la derecha del motivo } 13 \text {. Ejecutada mediante fina incisión y con } \\
\text { una forma muy sintética gracias a dos líneas casi paralelas, simulando el pecho y el } \\
\text { dorso, y rematadas por dos líneas unidas en el vértice que conformaron su acentuada } \\
\text { cabeza triangular, ligeramente redondeada en la quijada (Fig. 6). }\end{array}$ & 2,5 & I \\
\hline 15 & IV-1-7 & $\begin{array}{l}\text { Prótomo de cérvido en la extremidad superior derecha del panel. Ejecutado por trazos } \\
\text { finos y únicos, a veces repetidos. Tiene pocos detalles anatómicos. La figura, } \\
\text { orientada a la derecha del observador y ligeramente inclinada hacia arriba, conserva } \\
\text { un morro entre apuntado y redondeado, la recta línea cérvico-dorsal, el cuello-pecho } \\
\text { y el arranque de las extremidades anteriores. Destaca la forma ovalada de su cabeza } \\
\text { y las abundantes líneas grabadas por trazos repetidos y únicos observables en su } \\
\text { interior (Figs. 5-6). }\end{array}$ & 4 & I \\
\hline 16 & IV-1-7 & $\begin{array}{l}\text { Prótomo de équido inciso en trazo único y repetido, orientado hacia la derecha del } \\
\text { observador. Está en la parte izquierda del panel 7. La peculiar coloración del panel y su } \\
\text { defectuoso estado de conservación dificultan la observación, pero se perciben la línea } \\
\text { naso-frontal y la de la quijada, ambas rectas y ejecutadas con múltiples trazos incisos } \\
\text { continuos y discontinuos, y el morro apuntado. El animal carece, además, de reseñables } \\
\text { detalles anatómicos internos. Su pecho-cuello fue iniciado al igual que la doble crinera } \\
\text { enhiesta que tiene, al menos, } 40 \text { trazos que en algunos casos podrían corresponder tanto } \\
\text { a las orejas, inclinadas hacia adelante, como al tupé del équido (Figs. 5-6). }\end{array}$ & 20 & I \\
\hline 17 & IV-1-7 & $\begin{array}{l}\text { Prótomo de équido inciso con trazos únicos y repetidos, y orientado hacia la derecha. } \\
\text { Pese a las dificultades de observación, como en el équido anterior, se perciben la línea } \\
\text { naso-frontal y la quijada, aquí ambas ejecutadas por líneas en trazo único. El morro del } \\
\text { animal difiere del anterior por estar cerrado y su forma redondeada. Carece de detalles } \\
\text { anatómicos internos aunque su pecho-cuello fue iniciado por tres trazos, al menos. Su } \\
\text { crinera enhiesta tiene el mismo número de trazos que el équido anterior, simulando la } \\
\text { doble crinera, orejas inclinadas hacia adelante y tupé (Figs. 5-6). }\end{array}$ & 21 & I \\
\hline 18 & IV-1-7 & $\begin{array}{l}\text { Conjunto de pequeños trazos lineales paralelos y situados junto al redondeado morro } \\
\text { del équido inventariado como motivo } 17 \text { (Figs. } 5 \text { y } 6 \text { ). }\end{array}$ & 2 & I \\
\hline 19 & IV-1-7 & $\begin{array}{l}\text { Prótomo de équido inciso en trazos únicos y repetidos. Está orientado hacia la derecha } \\
\text { del observador, por encima del motivo } 17 \text {. Se perciben, como en los motivos anteriores, } \\
\text { la línea naso-frontal y la quijada convexa, ejecutadas ambas por varias líneas en trazos } \\
\text { únicos, repetidos, continuos y discontinuos. El morro del animal también es diferente al } \\
\text { de los otros prótomos de équidos del panel, motivos } 16 \text { y } 17 \text {, al tener una apuntada } \\
\text { forma abierta. La línea cérvico-dorsal, ligeramente cóncava, también se ejecutó con } \\
\text { trazos únicos, repetidos y continuos (Figs. } 5 \text { y 6). }\end{array}$ & 10 & I \\
\hline 20 & IV-1-7 & $\begin{array}{l}\text { Prótomo de équido ejecutado en trazos únicos, discontinuos y repetidos, y orientado } \\
\text { hacia la derecha. Pese a las dificultades de observación, y su parcial ejecución, se } \\
\text { perciben la línea naso-frontal, la quijada convexa, el morro redondeado y del arranque } \\
\text { de la crinera junto a varios posibles pelos hirsutos de esta (Figs. } 5 \text { y } 6 \text { ). }\end{array}$ & 14 & I \\
\hline 21 & IV-1-7 & $\begin{array}{l}\text { Zoomorfo acéfalo realizado en trazos únicos y repetidos, posiblemente un équido. Se } \\
\text { perciben la línea cérvico-dorsal recta, que incluye la grupa, y los abundantes trazos } \\
\text { utilizados para ejecutar el convexo vientre y simular la longitud del pelaje del animal, } \\
\text { indicándose, en el tren delantero, el arranque de las extremidades anteriores sin } \\
\text { completar. También ejecutaron el inicio de las extremidades posteriores y la cola como } \\
\text { continuación de la línea cérvido-dorsal. (Figs. } 5 \text { y 6). }\end{array}$ & 25 & I \\
\hline
\end{tabular}

Tab. 1.[2] Relación y descripción de los motivos paleolíticos grabados por incisión e inventariados en el sitio del Arroyo de las Almas (Fregeneda, Salamanca). Dim. Dimensiones.

Trab. Prehist., 76, N. ${ }^{\circ}$ 1, enero-junio 2019, pp. 138-146, ISSN: 0082-5638

https://doi.org/10.3989/tp.2019.12230 


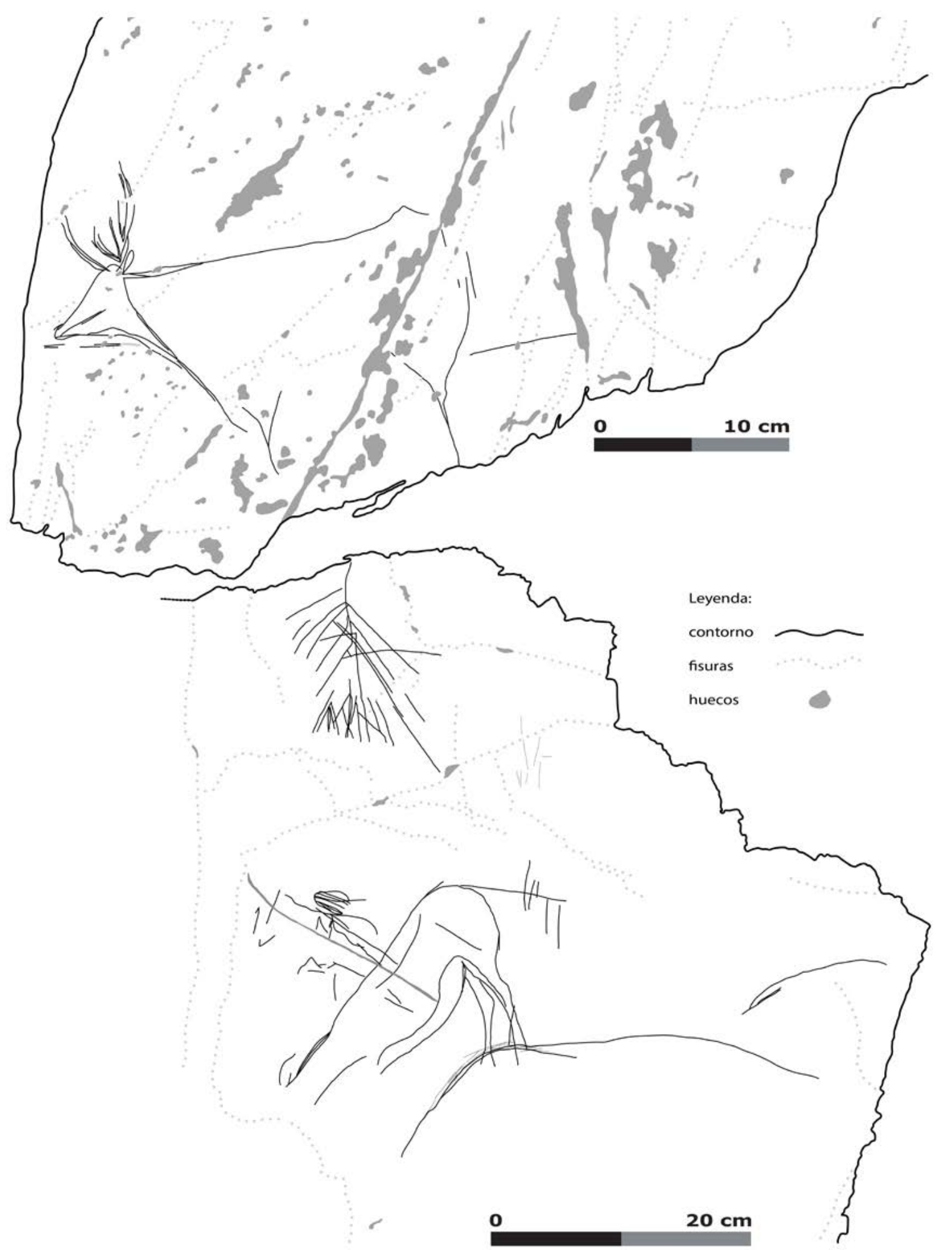

Fig. 4. Calcos parciales de los grabados paleolíticos del panel 1 de la roca 6 del Núcleo I (motivo 1, arriba) y del panel 2 de la roca 3 del Núcleo III (motivo 4, abajo). 


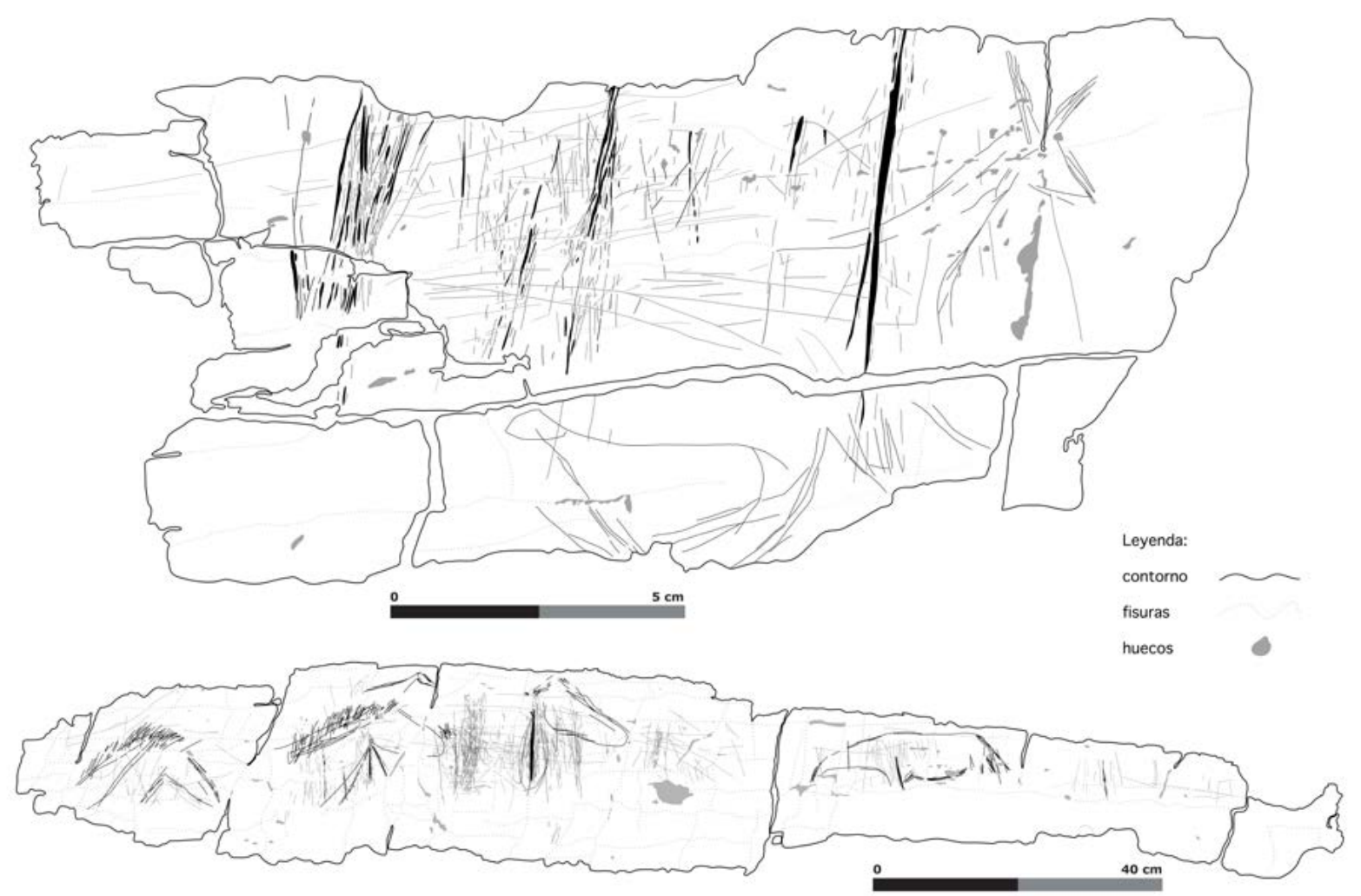

Fig. 5. Calcos parciales de los grabados paleolíticos de la Roca 1 del Núcleo IV: panel 6 (arriba) y 7 (abajo).

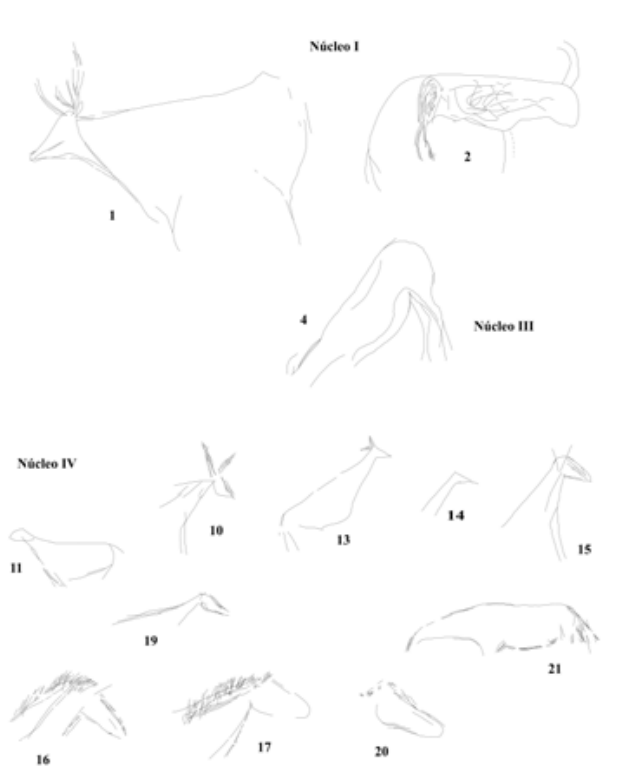

Fig. 6. Detalle de los 13 motivos zoomorfos paleolíticos del Arroyo de las Almas (sin indicación de escala; véase Tab. 1). junto. El despiece advertido en el motivo 4 (Figs. 4 y 6) es uno de ellos. Esta convención gráfica es asidua en el Magdaleniense de la península ibérica y no solo al aire libre. Lo mismo sucede con el motivo 2 (Fig. 6). La forma rectilínea del dorso y de la parte posterior, el uso del trazo múltiple en el rellenado corporal y de las extremidades posteriores, o el característico subnaturalismo sugieren una cronología tardía. El motivo se asemeja a algunas figuras de las placas de arte mueble del sitio de Fariseu, en el valle del Côa (Aubry 2009: 387, 389; Santos et al. 2018), estratigráficamente insertadas en una etapa transicional entre la segunda mitad del Tardiglaciar y el Holoceno temprano. Esta cronología ayuda a corroborar nuestra propuesta y la de otros enclaves del interior meseteño sobre estos mismos soportes (García Diez y Cacho 2015). Al menos 4 de los animales se han representado completos, siendo alguno acéfalo (motivo 4 y motivo 21, Fig. 6). Los demás se reducen al prótomo.

Todas las figuras documentadas emplean la incisión como técnica de grabado. Esto coincide con lo que ocurre en el resto del arte parietal paleolítico peninsular, donde la incisión es la modalidad preferentemente 
utilizada, aunque el piqueteado de contornos o la abrasión tengan un papel muy relevante en determinados enclaves.

El primer resultado de los análisis realizados es constatar una amplia diacronía de estos motivos, aunque la casi totalidad de ellos se encuadre en el Magdaleniense, estilos IV antiguo y IV reciente de LeroiGourhan, fase I del sitio de Arroyo de las Almas. Quizá, los primeros puedan situarse cronoculturalmente en un momento anterior al Magdaleniense antiguo, estilos III y IV antiguo, pero dado el carácter de esta aportación, no nos parece congruente ofrecer una cronología refinada y en detalle, más allá de una datación relativa que podría rondar los $17000 \mathrm{BP}$. Otro grupo de figuras debería de ser situado en los momentos finales del Paleolítico Superior, fase II del sitio. Un período que, entre otras terminologías, ha sido clasificado por algunos investigadores, siguiendo los postulados de A. Leroi-Gourhan, como un "estilo V", entre los 13000/12000 y 9000 BP (14000 y 10500 cal BP) (Bueno et al. 2008: 280). Además documentamos otras figuras, probablemente ejecutadas en momentos intermedios, lo que significa, si nuestra apreciación cronológica es correcta, que el conjunto rupestre paleolítico del Arroyo de las Almas perduró varios miles de años.

Hemos intentado recrear, con la inevitable incertidumbre connatural a un ejercicio de este género, lo que podría haber sido la evolución en la decoración del conjunto paleolítico del Arroyo de las Almas. Los primeros motivos serían los 3 prótomos de équidos, tipológicamente idénticos, catalogados en la roca 1 del Núcleo IV y posiblemente ejecutados de una vez y por una sola mano, en los momentos iniciales del Magdaleniense. Empero, no podemos afirmar que las siguientes figuras ejecutadas sean las de esta roca o las de otras de las inventariadas ya que durante las siguientes fases se van a realizar otras figuras, en esta roca del Núcleo IV (motivos 13, 14, 15, 19 y 21), en la roca 6 del Núcleo I (motivo 1) y en la roca 3 del Núcleo III (motivo 4). En las rocas 6 y 3 lo más probable es que las figuras correspondan al mismo período que las restantes representaciones, en particular signos y conjuntos de líneas. En la roca 1 del Núcleo IV, por contra, la ordenación cronológica de los signos y conjuntos de líneas es mucho más compleja aunque hay algunas asociaciones entre estas y las figuras zoomorfas. Por último, ya en los momentos finales del Tardiglaciar e inicios del Holoceno, la roca 1 del Núcleo IV vuelve a ser decorada, en esta ocasión en un pequeño panel periférico, con los motivos 10 y 11 . Es posible, pero difícil de demostrar que el motivo indeterminado de la roca 1 del Núcleo I (motivo 3) sea también de este período final del Paleolítico. Asimismo, teniendo en cuenta las características estilísticas del motivo 2, es admisible que esta peculiar figura zoomorfa sea la última de las ejecutadas en este período en la roca 7 del Núcleo I. Esta, es una superficie situada a pocos metros del cérvido de la roca 6 y en el mismo contexto paisajístico del desfiladero rocoso que fluye hacia la rivera, pero con una probable separación temporal de varios miles de años, entre el inicio y el final en la decoración de este nuevo conjunto paleolítico. Una extensión temporal que coincidiría con el yacimiento de Siega Verde y con muchos de los principales sitios del conjunto del valle del Côa.

\section{CONSIDERACIONES FINALES}

El descubrimiento del sitio rupestre de Arroyo de las Almas amplía a más de 80 los enclaves del Paleolítico Superior al aire libre en la península ibérica, una cifra que representa más del $30 \%$ de los lugares con arte paleolítico en este territorio, tanto en cueva, abrigo como al aire libre. Además es otro nuevo y sólido pilar argumentativo para desechar la repetida idea del arte paleolítico a la intemperie como un fenómeno minoritario y marginal pese a los innumerables resultados arqueológicos obtenidos en los últimos años (Aubry 2015; Alcolea y Balbín 2006; Bahn 2015; Balbín 2008; Baptista 1999, 2009; Figueiredo, Xavier et al. 2014; Figueiredo, Nobre et al. 2016; Garate et al. 2016; Reis 2012, 2013, 2014; Vázquez Marcos 2017; Welker 2016).

De igual modo, mencionar sobre las figuras documentadas y sus principales caracteres formales y estilísticos, su atribución cronocultural a dos diferentes fases. La fase I correspondería al Magdaleniense Antiguo y Reciente, con una cronología genérica, grosso modo, entre 17000 y $13000 / 12000 \mathrm{BP}$, y la fase II, desde los momentos finales del Tardiglaciar hasta el Holoceno temprano, con una cronología entre los 13000/12000 y 9000 BP. Acaso, el magnífico ejemplar localizado en el Núcleo I (motivo 4) y varios de los équidos del panel 7 de la roca 1 del Núcleo IV (motivos 16,17 y 20) podrían corresponder a un inicial momento transicional entre el Solutrense y el Magdaleniense si consideramos algunos paralelos sobre soportes parietales y muebles en el contexto arqueológico más cercano. Sin embargo, esta tarea, que esperamos poder justificar tras el mesurado análisis de todos los datos existentes en futuras publicaciones, superaría en esta nota nuestro objetivo principal: solucionar la cuestión cronología genérica del sitio.

Para finalizar, queremos insistir en las nuevas perspectivas en la investigación sobre el arte rupestre, preferentemente en la cuenca del Duero internacional, que abre este nuevo conjunto por su estratégica posición geográfica, como lugar de paso fundamental en la red de intercambios culturales y de materias primas 
de la región del Duero, preferentemente en los momentos de mayor crecimiento demográfico, innovaciones tecnológicas y cambios medioambientales.

\section{BIBLIOGRAFÍA}

Alcolea, J. J. y Balbín, R. de 2006: Arte paleolitico al aire libre. El yacimiento rupestre de Siega Verde, Salamanca. Arqueología en Castilla y León. Memorias 16, Junta de Castilla y León. Valladolid

Alcolea, J. J. y Balbín, R. de 2008: "El yacimiento rupestre de Siega Verde, Salamanca. Una visión de síntesis”. En R. de Balbín (ed.): Arte prehistórico al aire libre en el sur de Europa. Junta de Castilla y León. Valladolid: 57-87.

Aubry, T. (ed.). 2009: 200 séculos da história do Vale do Côa: incursões na vida quotidiana dos caçadores-artistas do Paleolítico. Trabalhos de Arqueologia 52. IGESPAR. Lisboa.

Aubry, T. 2015: "Peuplement de l'intérieur de la Péninsule Ibérique pendant le Paléolithique supérieur: où en est-on?". ARPI 03 Extra. Homenaje a Rodrigo de Balbín Behrmann: 20-31.

Bahn, P. 2015: "Open-air Ice Age art: the history and reluctant acceptance of an unexpected phenomenon". En P. Bueno y P. G. Bahn (eds.): Prehistoric Art as Prehistoric Culture. Studies in Honour of Professor Rodrigo de Balbin-Behrmann. Archaeopress. Oxford: 7992.

Balbín, R. de (ed.) 2008: Arte prehistórico al aire libre en el Sur de Europa. Serie Actas. Junta de Castilla y León. Valladolid.

Baptista, A. M. 1999: No tempo sem tempo: A arte dos caçadores paleolíticos do Vale do Côa. Com uma perspectiva dos ciclos rupestres pós-glaciares. Parque Arqueológico do Vale do Côa/Centro Nacional de Arte Rupestre. Vila Nova de Foz Côa.

Baptista, A. M. 2009: O paradigma perdido. O Vale do Côa e a Arte Paleolitica de Ar Livre em Portugal. Afrontamento. Lisboa.

Baptista, A. M. y Reis, M. 2011: "A rocha gravada de Redor do Porco. Um novo sítio com arte paleolítica de ar livre no rio Águeda (Escalhão, Figueira de Castelo Rodrigo)". Côavisão 13: 15-20.

Bueno, P.; Balbín, R. de. y Alcolea, J. J. 2008: "Estilo V en el ámbito del Duero: cazadores finiglaciares en Siega Verde (Salamanca)". En R. Balbín (ed.): Arte prehistórico al aire libre en el Sur de Europa. Junta de Castilla y León. Valladolid: 259-286.

Figueiredo, S.; Nobre, L.; Xavier, P.; Gaspar, R. y Carrondo, J. 2016: "First approach to the chronological sequence of the engraved stone plaques of the Foz do Medal alluvial terrace in Trás-os-Montes, Portugal". ARPI 04 Extra. Homenaje a Rodrigo de Balbín Behrmann: 64-77.

Figueiredo, S.; Xavier, P.; Silva, A.; Neves, D. y Domínguez, I. 2014: "The Holocene transition and post-palaeolithic rock art from the Sabor Valley (Trás-os-Montes, Portugal)". En M. A. Medina-Alcaide, A. J. Romero Alonso, R. M. Ruiz-Márquez y J. L. Sanchidrián Torti (eds.): Sobre rocas y huesos: las sociedades prehistóricas y sus manifestaciones plásticas. Imprenta Luque. Córdoba: 193-203.
Garate, D.; Rios Garaizar, J.; Pérez, R.; Rojas, R. y Santonja, M. 2016: "Arte rupestre paleolítico al aire libre en el paraje de La Salud (valle del Tormes, Salamanca)". Zephyrus 77: 15-29. https://doi. org/10.14201/zephyrus2016771529

García Diez, M. y Cacho, C. 2015: "Beyond Leroi-Gourhan's Style IV: portable art at La Peña de Estebanvela Rock-shelter (Segovia, Spain)". Journal of Anthropology and Archaeology 3 (1): 23-36. https://doi.org/10.15640/jaa.v3n1a2

Leroi-Gourhan, A. 1971. Préhistoire de l'art occidental. Éditions d'Art Lucien Mazenod. Paris.

Reis, M. 2012: "Mil rochas e tal...!: Inventário dos sítios da arte rupestre do vale do Côa". Portvgalia 33: 5-72.

Reis, M. 2013: "Mil rochas e tal...!: Inventário dos sítios da arte rupestre do vale do Côa ( $2^{\circ}$ parte)". Portvgalia 34: 5-68.

Reis, M. 2014: "Mil rochas e tal...: Inventario dos sítios da arte rupestre do vale do Côa (conclusão)". Portvgalia 35: 17-59.

Reis, M. y Vázquez Marcos, C. 2015: “Arte rupestre en la frontera hispano-portuguesa: cuenca del río Águeda". ARPI 03 Extra. Homenaje a Rodrigo de Balbín Behrmann: 32-43.

Ripoll, S. y Municio, L. (eds.) 1999: Domingo García. Arte Rupestre Paleolítico al aire libre en la meseta castellana. Arqueología en Castilla y León. Memorias 8. Junta de Castilla y León. Valladolid.

Rivero, O. y Sauvet, G. 2014: "Defining Magdalenian cultural groups in Franco-Cantabria by the formal analysis of portable artworks". Antiquity 88 (339): 64-80. https://doi.org/10.1017/s0003598x00050225

Santos, A. T. P. S. C. 2017: A arte paleolitica ao ar livre da bacia do Douro à margem direita do Tejo: uma visão de conjunto. Tesis doctoral, Universidad de Porto._http://hdl.handle.net/10216/109327

Santos, A. T.; Aubry, T.; Barbosa, A. F.; García Diez, M. y Sampaio, J. D. 2018: "O final do ciclo gráfico paleolítico do Vale do Côa: A arte móvel do Fariseu (Muxagata, Vila Nova Foz Côa)". Portvgalia 39: 5-96.

Teixeira, J. C. y Sanches, M. J. 2017: "O abrigo rupestre da foz do rio Tua no contexto da arte paleolítica e pós-paleolítica do Noroeste da Península Ibérica”. Portvgalia 38: 9-48.

Vázquez Marcos, C. 2014: "Análisis estadístico del caballo en el sitio de Siega Verde”. En M. S. Corchón y M. Menéndez (eds.): Cien años de arte rupestre paleolitico. Universidad de Salamanca. Salamanca: 273-283.

Vázquez Marcos, C. 2015: “Análisis estadístico de las grafías figurativas zoomorfas de cabras grabadas en el sitio arqueológico de Siega Verde (Serranillo, Salamanca, España)". En H. Collado y J. G. Arranz (eds.): Actas del XIX International Rock Art Conference. IFRAO. ARKEOS 37. Cáceres: 847-862.

Vázquez Marcos, C. 2017: 'Despieces ventrales 'en M' en las representaciones peninsulares de équidos superopaleolíticos”. Sautuola XIX: 471-500.

Welker, W. 2016: "First Palaeolithic rock art in Germany: engravings on Hunsrück slate”. Antiquity 90 (349): 32-47. https://doi.org/10.15184/ aqy. 2015.136

Trab. Prehist., 76, N. ${ }^{\circ}$ 1, enero-junio 2019, pp. 138-146, ISSN: 0082-5638

https://doi.org/10.3989/tp.2019.12230 